\title{
Erosion of tungsten-doped amorphous carbon films exposed to deuterium plasmas
}

\author{
P. Wang, W. Jacob* , M. Balden, T. Höschen, A. Manhard \\ Max-Planck-Institute für Plasmaphysik, EURATOM Association, Boltzmannstr.2, 85748 Garching, Germany
}

\begin{abstract}
:
Tungsten-doped amorphous carbon films with 0-9.5 at.\% W concentration were produced by magnetron sputtering and exposed to deuterium plasmas applying different ion energies and fluences. The partial $\mathrm{C}$ and $\mathrm{W}$ erosion rates were determined from the $\mathrm{C}$ and $\mathrm{W}$ areal density changes, respectively, measured by Rutherford backscattering spectrometry. For W-doped films the erosion rate decreases with increasing $\mathrm{W}$ concentration and incident fluence. During deuterium plasma exposure carbon is preferentially eroded while tungsten atoms accumulate at the surface leading to the formation of a W-rich layer, which decreases the removal efficiency and leads to a continuous decrease of the erosion rate. At $30 \mathrm{eV} / \mathrm{D}$ incident energy a relatively compact $\mathrm{W}$-rich layer is formed on films with higher $(\geq 5 \%) \mathrm{W}$ concentration which protects the carbon underneath from further erosion. For films with lower $(\leq 2.5 \%) \mathrm{W}$ concentration the erosion rate decreases, but the erosion process does not stop because the Wrich layer has a high porosity. Reactive neutral species can penetrate through this porous layer and react with carbon atoms below it. At $100 \mathrm{eV} / \mathrm{D}$ incident energy the erosion rate is significantly higher compared with $30 \mathrm{eV} / \mathrm{D}$. In addition, slight tungsten sputtering is observed due to the presence of a small fraction of $\mathrm{D}^{+}$plasma ions which impinge with $300 \mathrm{eV} / \mathrm{D}$.
\end{abstract}

Keywords: Tungsten-doped carbon films; Deuterium plasma; Erosion

PACS: 52.40.Hf, 81.65.Cf, 82.65.+r, 52.77.Bn

Published in: Journal of Nuclear Materals, 426, 277-286 (2012).

doi: $\quad$ 10.1016/j.jnucmat.2012.03.043

Submitted: $\quad 29.02 .2012$

Accepted: $\quad 29.03 .2012$

Available online 19 April 2012

\footnotetext{
${ }^{*}$ Corresponding author. Fax:+49-3299-1504, Tel:+49-3299-2618.

E-mail address: wolfgang.jacob@ipp.mpg.de
} 


\section{Introduction}

The plasma-facing surfaces provide the boundary conditions that govern the performance of any magnetically confined plasma device. The importance of these material surfaces will continue to increase as devices push toward higher and higher power and longer discharge duration [1]. Based on the observation in present fusion devices, it is expected that the wall materials will be eroded due to the interaction with plasma species and subsequently codeposited with hydrogen isotopes on other material surfaces [2-7]. This leads to the formation of mixed deposition layers on the first-wall surfaces. Actually, co-deposition of tritium with material eroded from the plasma-facing components in deposition-dominated areas is expected to be the main contribution to the tritium inventory in ITER [7-10]. According to the ITER design review, carbon fiber composite (CFC) and tungsten have been chosen as the plasma-facing materials for the ITER divertor [11]. The use of carbon materials together with tungsten will lead to cycles of erosion of the plasma-facing materials and subsequent deposition of mixed carbon-tungsten layers. These mixed layers will be partly on areas subjected to further erosion. Therefore, the erosion behaviour and deuterium retention of such mixed layers needs to be investigated.

In this article, tungsten-doped amorphous carbon $(a-\mathrm{C}: \mathrm{W})$ films deposited by magnetron sputtering were used as model systems for tungsten-containing redeposited layers. The carbon erosion behaviour of tungsten-doped carbon films exposed to deuterium plasma was investigated as a function of tungsten concentration, ion energy and incident fluence.

\section{Experimental details}

Pure and tungsten-doped amorphous carbon films with thicknesses between 600 and $800 \mathrm{~nm}$ were deposited onto single crystalline (100) silicon wafers using a commercial sputtering device (Discovery ${ }^{\circledR} 18$, Denton) comprising three individually controllable magnetrons. For the deposition of $a-\mathrm{C}: \mathrm{W}$ films two of these magnetrons were used, one holding a graphite and the other a tungsten target. Argon was used as sputtering gas. The rf power applied to the graphite target was kept constant at $500 \mathrm{~W}$, and the dc power applied to the tungsten target was varied from 0 to $8 \mathrm{~W}$ to produce pure carbon films and tungsten-doped carbon films with different tungsten concentration up to 9.5 at $\% \mathrm{~W}$. No extra substrate bias and heating were applied during deposition. More details of the deposition procedure can be found in Ref. [12], and an overview of the layer properties in Refs. [13, 14].

The deuterium plasma exposures were carried out in the laboratory plasma experiment $\mathrm{PlaQ}$. A basic description of PlaQ is given in [15-17]. In short, PlaQ consists of a stainless steel chamber and is equipped with a remote electron cyclotron resonance (ECR) plasma source. Microwaves $(2.45 \mathrm{GHz})$ are coupled into the vacuum vessel from the high B-field side through a waveguide terminated by a quartz window. The magnetic field is created by a single magnetic coil. To decouple the plasma from the substrate, the plasma is confined in a metallic cage $150 \mathrm{~mm}$ in height and $140 \mathrm{~mm}$ in diameter. Particles can leave the cage in an axial direction through a hole in the bottom plate with a diameter of $55 \mathrm{~mm}$. A diverging plasma beam impinges perpendicularly onto the substrates which are located $100 \mathrm{~mm}$ below the cage exit. The energy of the ions impinging on the substrates can be varied by applying a dc or rf bias to the substrate electrode.

To ensure identical conditions in all erosion processes, the microwave output power for the ECR plasma was set to $144 \mathrm{~W}$ with a constant $\mathrm{D}_{2}$ gas pressure prior to plasma ignition of $1 \mathrm{~Pa}$ (gas flow $50 \mathrm{sccm}$ ). At floating potential, the total deuteron flux in the form of ions is $5.6 \times 10^{19} \mathrm{Dm}^{-2} \mathrm{~s}^{-1}$, the flux consisted dominantly of $\mathrm{D}_{3}{ }^{+}$ions $(97 \%$ of the impinging deuterons) with minor contributions of $\mathrm{D}_{2}^{+}(2 \%)$ and $\mathrm{D}^{+}(1 \%)$ [17]. The species composition was measured to be independent of the bias voltage for dc biasing [17]. Because the formation of molecular ions is dominated by ion-molecule reactions in the plasma volume and during transport to the surface it is mostly influenced by the neutral gas pressure [17]. We, therefore, 
assume that the composition of the ion flux is the same also for $\mathrm{rf}$ biasing. In this article we refer to the energy per deuterium atom of the dominant molecular ion species as the ion energy. For example, if the implantation was performed at $-75 \mathrm{~V}$, bias this produces, together with the plasma potential (-15 V [17]), ions with an energy of about $90 \mathrm{eV}$. This corresponds to a mean energy of $30 \mathrm{eV}$ per deuteron for the dominant $\mathrm{D}_{3}{ }^{+}$ions. In the experiments reported here $\mathrm{rf}$ bias was used to avoid arcing problems which arose because the samples are electrically insulating. The application of an $\mathrm{rf}$ voltage to the substrate electrode causes the formation of a dc self-bias voltage $\left(\mathrm{V}_{\mathrm{sb}}\right)$ such that the substrate holder is always negative relative to the plasma potential. The bias voltages given in this article are these dc self-bias voltages created by the applied rf power. Due to the polarity they are quoted as negative numbers. The corresponding mean ion energy is approximately the sum of the absolute values of the dc self-bias voltage and the plasma potential.

The deuterium ion fluxes at dc biases ranging from several volts up to $-600 \mathrm{~V}$ were thoroughly quantified with a retarding-field analyzer and an energy-resolving mass spectrometer [17]. However, the ion flux at $\mathrm{rf}$ bias is more difficult to measure compared to the ion flux at dc bias condition. Here an alternative method based on measuring the sputtering yield of a copper film was used to determine the ion flux at rf bias. A copper film with a thickness of $1000 \mathrm{~nm}$ deposited on silicon substrate was used as reference material. The removed copper amount for defined values of the self-bias voltage was measured by ion beam analysis. From the known sputtering yield of copper by deuterium [18], the absolute particle flux can be determined by measuring the removed copper atom amount during defined sputtering times. Using this method deuterium ion fluxes for both, $\mathrm{rf}$ and $\mathrm{dc}$ bias conditions, were measured applying otherwise identical conditions. In particular, the time for pumping down the system after loading the samples, the pre-heating of the substrate holder and samples ( 24 hours at $370 \mathrm{~K}$ ), which is applied to desorb impurities (dominantly water) from the samples and the holder, and the total sputtering time were the same for both bias conditions. This procedure was chosen to minimize the possible influence of impurity sputtering on the measured copper erosion rates. The results show that in the whole investigated bias range ( -100 to $-600 \mathrm{~V}$ bias) the ion fluxes at $\mathrm{rf}$ bias condition are only $55 \%$ of the ion fluxes at dc bias. Consequently, the ion fluxes at $\mathrm{rf}$ bias were calibrated by multiplying the ion fluxes determined by Manhard et al. [17] for dc bias conditions by a factor of 0.55 . For the applied discharge pressure of $1 \mathrm{~Pa}$ and nominal microwave power of $144 \mathrm{~W}$ the total deuteron fluxes in form of ions are in our experiments: $4.8 \times 10^{19} \mathrm{D} \mathrm{m}^{-2} \mathrm{~s}^{-1}$ at $\mathrm{V}_{\mathrm{sb}}=$ $75 \mathrm{~V}(30 \mathrm{eV} / \mathrm{D})$ and $5.8 \times 10^{19} \mathrm{D} \mathrm{m}^{-2} \mathrm{~s}^{-1}$ at $\mathrm{V}_{\mathrm{sb}}=-285 \mathrm{~V}(100 \mathrm{eV} / \mathrm{D})$.

The surface morphology of films before and after deuterium plasma exposure was studied by atomic force microscopy (AFM) in non-contact mode (MFP-3D ${ }^{\mathrm{TM}}$, Asylum Research). AC cantilevers with pyramidal $\mathrm{Si}_{3} \mathrm{~N}_{4}$ tips with tip radius of curvature $<10 \mathrm{~nm}$ were used. The open-source software Gwyddion was applied for raw data processing. Roughness was quantified using the root mean square (RMS) value.

In order to detect morphological changes cross-sections of the plasma-exposed films were imaged with scanning electron microscopy (SEM). The used microscope (Helios NanoLab 600, FEI) allows the cross-sectioning in situ by the implemented focused ion beam (FIB). The secondary electrons produced by a $5 \mathrm{keV}$ electron beam were detected by the inlens detector system. The cross sections were imaged with the e-beam tilted by $38^{\circ}$ to their surface plane, so that the vertical scale in the shown images is compressed relative to the horizontal scale. Before the cross-sectioning by FIB, the specimens were covered with a roughly $1 \mu \mathrm{m}$ thick $\mathrm{Cu}$ layer deposited by magnetron sputtering without substrate bias and heating. This coating leads to a clear contrast between the $a-\mathrm{C}: \mathrm{W}$ film and the $\mathrm{Cu}$ coating. Furthermore, a Pt-C layer is coated on top of the $\mathrm{Cu}$ to obtain sufficiently flat cross-sections.

Rutherford backscattering spectrometry (RBS) was applied to measure the elemental composition of the films before and after erosion. A beam of $4.0 \mathrm{MeV}{ }^{4} \mathrm{He}$ was used at a 
scattering angle of $165^{\circ}$, and a charge of $15 \mu \mathrm{C}$ was usually accumulated for one $\mathrm{RBS}$ spectrum. In some cases, a $70^{\circ}$ degree incident angle instead of normal incidence to the surface was applied in RBS analysis to enhance the sensitivity for thin films at the surface. The spectra were simulated using the program SIMNRA 6.05 [19]. The film composition is determined in atomic percent. The tungsten concentration of the used films varies between 0 and approximately 10 at. \%. For convenience, the notation being used throughout the text to describe a tungsten-doped amorphous carbon film containing $\mathrm{x}$ at. $\%$ tungsten is " $\mathrm{x} \% a-\mathrm{C}: \mathrm{W}$ ".

X-ray photoelectron spectroscopy (XPS) was carried out on a PHI5600 system using a $\mathrm{Al} \mathrm{Ka}$ source. The photoelectron spectra were measured with a hemispherical analyzer operating at pass energy of $23.5 \mathrm{eV}$. The binding energy scale was calibrated with the $\mathrm{Au} 4 \mathrm{f}_{7 / 2}$ peak at $84.0 \mathrm{eV}$, the $\mathrm{Ag} 3 \mathrm{~d}_{5 / 2}$ peak at $368.3 \mathrm{eV}$, and the $\mathrm{Cu} 2 \mathrm{p}_{3 / 2}$ peak at $932.7 \mathrm{eV}$. Depth profiles were acquired by sputtering with a scanning $3 \mathrm{keV} \mathrm{Ar}^{+}$ion beam. The sputtered area was about $1 \times 1 \mathrm{~mm}^{2}$, and the ion beam current on the target was about $140 \mathrm{nA}$, i.e., a flux of $9 \times 10^{17} \mathrm{Ar} \mathrm{m}^{-2} \cdot \mathrm{s}^{-1}$. The elemental compositions of the sputtered surfaces were determined in dependence of the $\mathrm{Ar}^{+}$fluence from the evaluation of the data by a commercial software package [20]. Unfortunately, the sputter time cannot be converted to a depth scale because the sputter yield of the mixed and porous layers are presently not known.

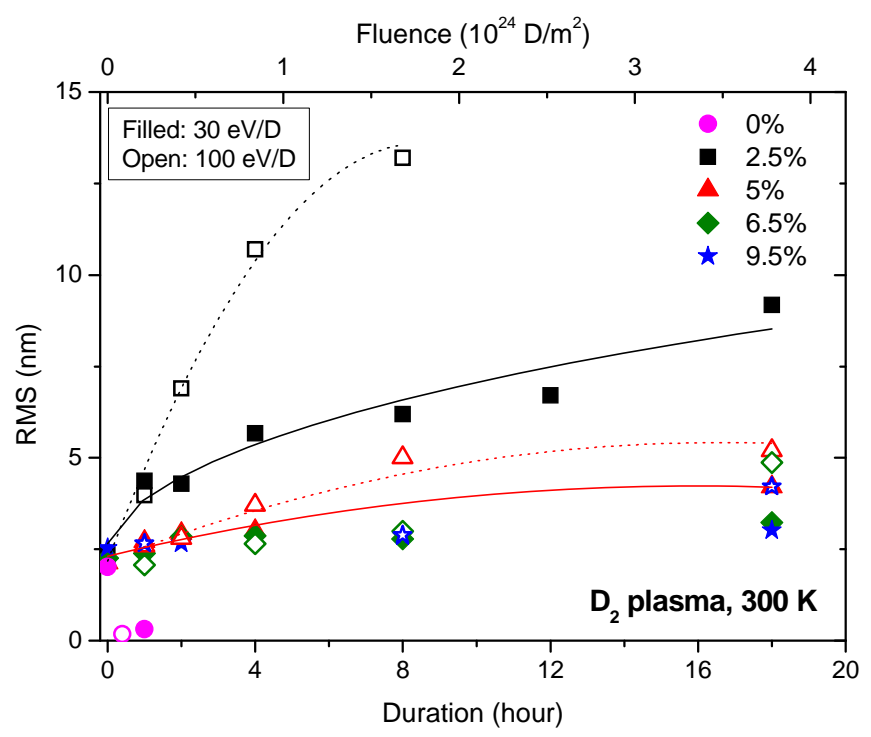

Fig. 1. Summary of surface roughness (RMS) of a-C and a-C:W films (600 to $800 \mathrm{~nm}$ thick) exposed to deuterium plasmas at 30 (filled symbols) and $100 \mathrm{eV} / \mathrm{D}$ (open symbols) incident particle energies as a function of exposure duration. Different symbols correspond to different $W$ fractions. The lines plotted for $2.5 \%$ and $5 \%$ a-C: $W$ films are a guide to the eye. The fluence scale given on the top axis corresponds to $100 \mathrm{eV} / \mathrm{D}$ incident energy case. The fluence for the $30 \mathrm{eV} / \mathrm{D}$ case is about $17 \%$ lower.

\section{Results and discussion}

\subsection{Surface morphology and cross-sections}

Because of the generally low surface roughness the morphology of the eroded samples was mainly studied by AFM. The roughness measured by AFM was in the following taken into account for simulation of the RBS spectra. Fig. 1 summarizes the RMS surface roughness as a function of exposure duration for all $a-\mathrm{C}$ and $a-\mathrm{C}: \mathrm{W}$ films. The accumulated fluence for the $100 \mathrm{eV} / \mathrm{D}$ condition is also shown on the top axis of Fig. 1. It can be see that the initial surfaces of all films have comparable roughness of about $2.5 \mathrm{~nm}$, regardless whether pure or tungsten-doped carbon films are investigated. For $a-\mathrm{C}$ films, exposure to deuterium plasma leads to an extremely smooth surface, its RMS value decreases from 2.2 to $0.3 \mathrm{~nm}$ for 
$30 \mathrm{eV} / \mathrm{D}$. For $100 \mathrm{eV} / \mathrm{D}$ this smoothening process is even stronger $(<0.2 \mathrm{~nm})$. For comparison, typical values for the initial silicon wafers are below $0.2 \mathrm{~nm}$. The change of the surface roughness for tungsten-doped carbon films is quite different. All tungsten-doped carbon films become rougher with increasing deuterium fluence. Lower $\mathrm{W}$ concentration causes stronger roughness increase. Furthermore, the increase of roughness is for the same $\mathrm{W}$ concentration more significant at higher incident energy.
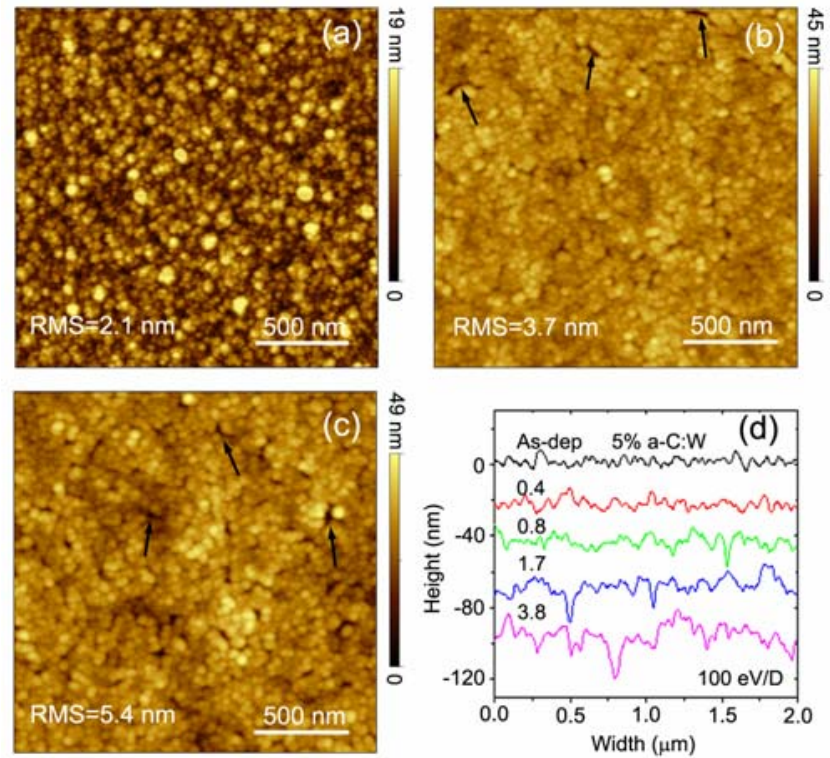

Fig. 2. $2 \times 2 \mu \mathrm{m}^{2}$ AFM images of $5 \%$ a-C:W films (740 $\mathrm{nm}$ thick) exposed to deuterium plasma at $100 \mathrm{eV} / \mathrm{D}$ with different incident fluence, (a) 0 , (b) $8.4 \times 10^{23}$, (c) $3.8 \times 10^{24} \mathrm{D} / \mathrm{m}^{2}$, corresponding vertical scale bars are included in each figure. Some micro-holes or micro-gaps are indicated by arrows. The evolution of the surface profiles is shown in Fig. 2d; the corresponding incident fluence (in units of $10^{24} \mathrm{D} / \mathrm{m}^{2}$ ) is indicated by the numbers in Fig. $2 d$.

The evolution of AFM images and surface profiles for 5\% a-C:W films exposed to deuterium plasma at $100 \mathrm{eV} / \mathrm{D}$ incident energy are shown in Fig 2. The initial surfaces of all investigated $a-\mathrm{C}: \mathrm{W}$ films are morphologically similar. They consist of relatively large and rounded clusters. These films display similar roughness and have grains with an average size of about $50 \mathrm{~nm}$ as shown in Fig. 2a. The morphology dramatically changes after exposure; a lot of micro-holes or micro-gaps emerge at the granular-morphology-dominated surface (Figs. $2 \mathrm{~b}$ and $\mathrm{c}$ ). The RMS roughness values of $5 \% a-\mathrm{C}: \mathrm{W}$ films rise from 2.3 to $3.7 \mathrm{~nm}$ already after exposure to a fluence of $8.4 \times 10^{23} \mathrm{D} / \mathrm{m}^{2}$ (corresponding to $4 \mathrm{~h}$ exposure) and then increases gradually with further exposure (Fig. 1). The evolution of the surface profile shown in Fig. 2d also reflects the change of surface roughness, the surface height difference of asdeposited $5 \% a-\mathrm{C}: \mathrm{W}$ film fluctuates in the range of several nanometers, after deuterium plasma exposure a rough surface was formed and the fluctuation was enlarged by a factor of 4 .

Surfaces and cross-sections of plasma-exposed films were investigated with scanning electron microscopy. Figs. 3 to 5 present images of some surfaces and cross-sections of a$\mathrm{C}: \mathrm{W}$ films with three different $\mathrm{W}$ concentrations after exposure to deuterium plasma at $30 \mathrm{eV} / \mathrm{D}$ and $100 \mathrm{eV} / \mathrm{D}$ incident energy. After deuterium exposure W-rich layers (details of the formation of this W-rich layer will be discussed later) are formed at the surface of the films. However, the structure and thickness of the W-rich layers are quite different. They depend strongly on the initial $\mathrm{W}$ concentration and on the energy of the impinging ions. 


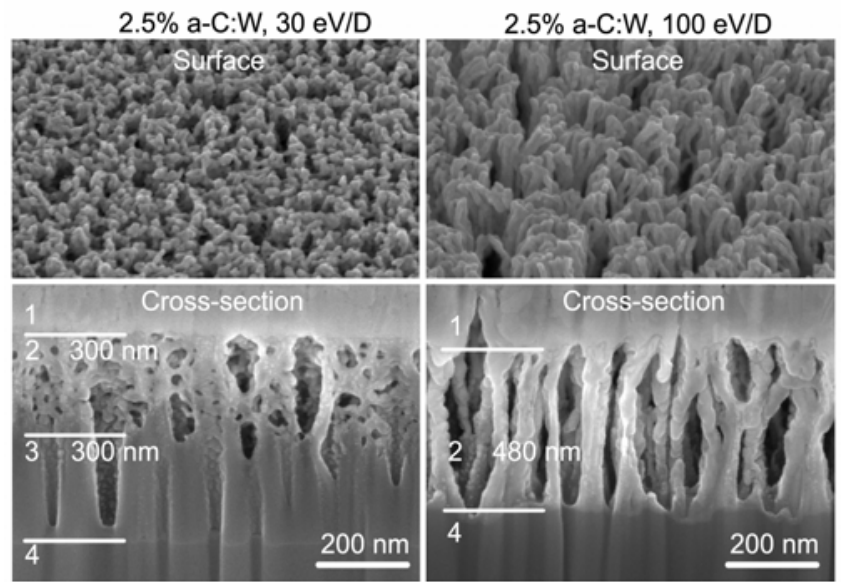

Fig. 3. Surface and cross-section SEM images of 2.5\% a-C:W films (initial film thickness $=$ $760 \pm 20 \mathrm{~nm})$ after exposure to deuterium plasma at $(a, b) 30$ and $(c, d) 100 \mathrm{eV} / \mathrm{D}$ incident particle energy with fluences of $3.1 \times 10^{24} \mathrm{D} / \mathrm{m}^{2}$ and $1.7 \times 10^{24} \mathrm{D} / \mathrm{m}^{2}$, respectively. The three interfaces and transitions between the Cu cover layer (1), the tungsten-enriched layer of the a$C: W$ film (2), the remaining unchanged a-C:W film (3), and the Si substrate (4) are marked with dotted lines. Note that the angle between the electron beam and the sample surface respectively the cross-section plane is $52^{\circ}$ and $-38^{\circ}$.

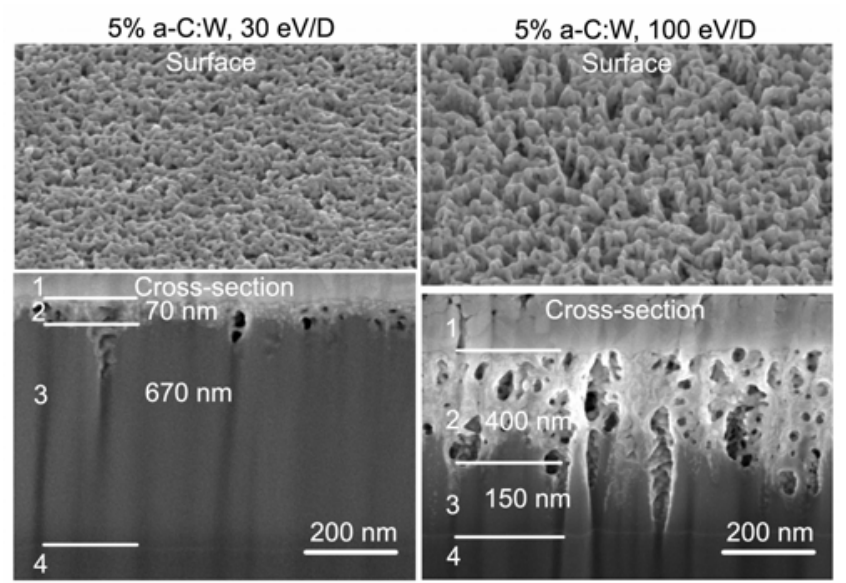

Fig. 4. Surface and cross-section SEM images of 5\% a-C:W films (initial film thickness = $740 \pm 20 \mathrm{~nm}$ ) after exposure to deuterium plasma at $(a, b) 30$ and $(c, d) 100 \mathrm{eV} / \mathrm{D}$ incident particle energy with fluences of $3.1 \times 10^{24} \mathrm{D} / \mathrm{m}^{2}$ and $3.8 \times 10^{24} \mathrm{D} / \mathrm{m}^{2}$, respectively. Further descriptions see Fig. 3.

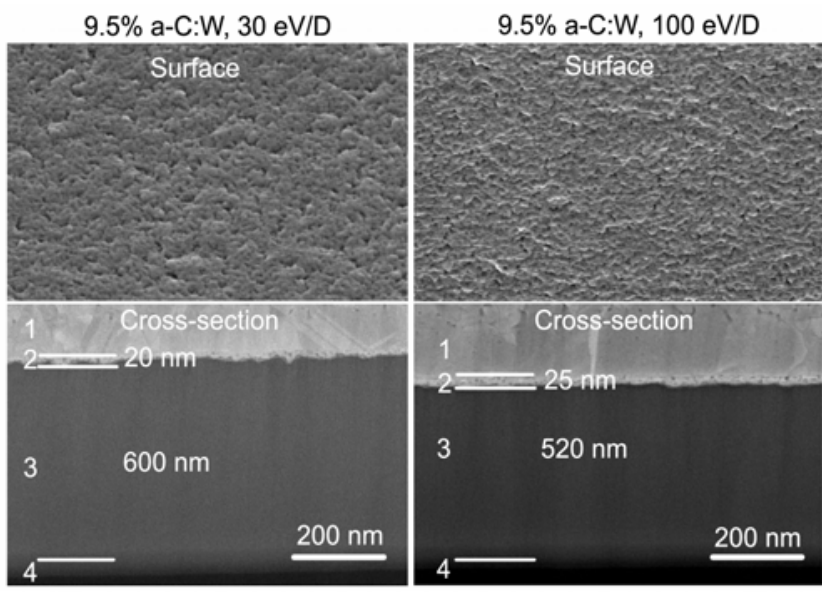

Fig. 5. Surface and cross-section SEM images of $9.5 \%$ a-C:W films (initial film thickness $=$ $680 \pm 20 \mathrm{~nm})$ after exposure to deuterium plasma at $(a, b) 30$ and $(c, d) 100 \mathrm{eV} / \mathrm{D}$ incident particle energy with fluences of $3.1 \times 10^{24} \mathrm{D} / \mathrm{m}^{2}$ and $3.8 \times 10^{24} \mathrm{D} / \mathrm{m}^{2}$, respectively. Further descriptions see Fig. 3. 
First we discuss the results after exposure to $30 \mathrm{eV} / \mathrm{D}$ incident energy with a fluence of $3.1 \times 10^{24} \mathrm{D} / \mathrm{m}^{2}$ (left-hand side images in Figs. 3 to 5). The thickness of the as-deposited films was measured by profilometry and after plasma exposure it was determined by SEM. The surface image of the $2.5 \% a$-C:W film (Fig. 3a) shows a homogeneous granular structure with grain sizes of several $10 \mathrm{~nm}$. The thickness of this film before plasma treatment was $760 \pm 20 \mathrm{~nm}$, it decreased to about $600 \mathrm{~nm}$ (including the about $300 \mathrm{~nm}$ W-rich layer) after exposure to a fluence of $3.1 \times 10^{24} \mathrm{D} / \mathrm{m}^{2}$. It is difficult to define the interface between the $\mathrm{W}$ rich layer and the remaining $a-\mathrm{C}: \mathrm{W}$ film because the corresponding cross-section image (Fig. $3 b$ ) shows a highly porous structure. In the direction parallel to the surface pores with sizes from several $\mathrm{nm}$ up to nearly one hundred $\mathrm{nm}$ are irregularly distributed. In the direction normal to the substrate some holes penetrating the whole layer are observed. The smaller pores occur only in the upper $300 \mathrm{~nm}$, therefore we attribute these upper $300 \mathrm{~nm}$ to the W-rich layer and the lower $300 \mathrm{~nm}$ to the carbon-dominated layer. The initial thickness of the $5 \% \mathrm{a}$ $\mathrm{C}: \mathrm{W}$ film was $740 \pm 20 \mathrm{~nm}$. After exposure the total thickness of the film remains largely unchanged (Fig. 4b), $670 \mathrm{~nm}$ are still original $a-\mathrm{C}: \mathrm{W}$ film and the thickness of the W-rich layer is about $70 \mathrm{~nm}$. Although the structure of the W-rich layer concluded both from the surface and the cross-section image (Fig. 4a and b) is more compact compared with the Wrich layer of the $2.5 \% a$-C:W film (Figs. $3 \mathrm{a}$ and $\mathrm{b}$ ), some holes along the normal direction are still visible. But the dimensions and the density are smaller compared with the $2.5 \% a$-C:W film. For the $9.5 \% a$-C:W film the initial thickness was $680 \pm 20 \mathrm{~nm}$. Both surface and crosssection images (Figs. 5a and b) show a compact and about $20 \mathrm{~nm}$ thin W-rich layer. The interface between the $\mathrm{W}$-rich layer and original $a-\mathrm{C}: \mathrm{W}$ films is relatively sharp. Below the $\mathrm{W}$ rich layer we find about $600 \mathrm{~nm}$ of the original $a-\mathrm{C}: \mathrm{W}$ film.

In the following we present the results for $100 \mathrm{eV} / \mathrm{D}$ (right-hand side images in Figs. 3 to 5). The different samples were exposed to different fluences due to the strongly varying erosion yields. The $2.5 \% a-\mathrm{C}: \mathrm{W}$ film (Figs. $3 \mathrm{c}$ and $\mathrm{d}$ ) was exposed to a fluence of $1.7 \times 10^{24} \mathrm{D} / \mathrm{m}^{2}$. After this exposure the carbon atoms from this film are completely removed. The remaining $\mathrm{W}$ atoms accumulated at the substrate surface. The thickness of this porous $\mathrm{W}$ layer determined by the cross-section image (Fig. 3d) is about $480 \mathrm{~nm}$. The $\mathrm{W}$ atoms form a columnar nano-brush-like structure with column diameters of about 30 to $50 \mathrm{~nm}$ and with heights from tens to hundreds of nanometers. The surface and cross-section images of the $5 \% a-\mathrm{C}: \mathrm{W}$ film after exposure to a fluence of $3.8 \times 10^{24} \mathrm{D} / \mathrm{m}^{2}$ are shown in Figs. $4 \mathrm{c}$ and $\mathrm{d}$. Compared with the lower energy condition (Figs. 4a and b) the W-rich layer formed at $100 \mathrm{eV} / \mathrm{D}$ is much thicker and a porous structure comparable to the one for the $30 \mathrm{eV} / \mathrm{D}$ of the $2.5 \%$ film (Figs. $3 \mathrm{a}$ and $\mathrm{b}$ ) is found. The surface and cross-section images of the $9.5 \% a-\mathrm{C}: \mathrm{W}$ film (Figs. $5 \mathrm{c}$ and d) exposed to a fluence of $3.8 \times 10^{24} \mathrm{D} / \mathrm{m}^{2}$ are quite similar compared with the corresponding lower incident energy exposure (Figs. 5a and b). No porous structure is visible below the W-rich layer (thickness about $25 \mathrm{~nm}$ ), but obviously the thickness of the remaining film is reduced.

\subsection{Chemical state and depth profile}

Sputter-XPS was used to derive some information about the chemical bonding and composition depth profiles of a-C:W films before and after plasma erosion. An Ar+ ion beam with $3 \mathrm{keV}$ energy was used to sputter the film and C 1s, W 4f, O 1s and Si 4s XPS signals were detected in certain intervals. One unavoidable disadvantage for ex-situ XPS measurement is oxygen and carbon contamination of the surface due to air exposure during sample transport through ambient atmosphere. Fig. 6 shows the composition depth profile of (a) $2.5 \%$ and (c) $5 \%$ a-C:W films after exposure to 30 and $100 \mathrm{eV} / \mathrm{D}$ incident particle energies with fluences of $3.1 \times 1024$ and $3.8 \times 1024 \mathrm{D} / \mathrm{m} 2$, respectively. Both samples are the identical samples for which the cross-section images are presented in Figs. 3a, b and Fig. 4c, d, respectively. Both XPS sputter depth profiles show that a W-rich layer formed at the surface 


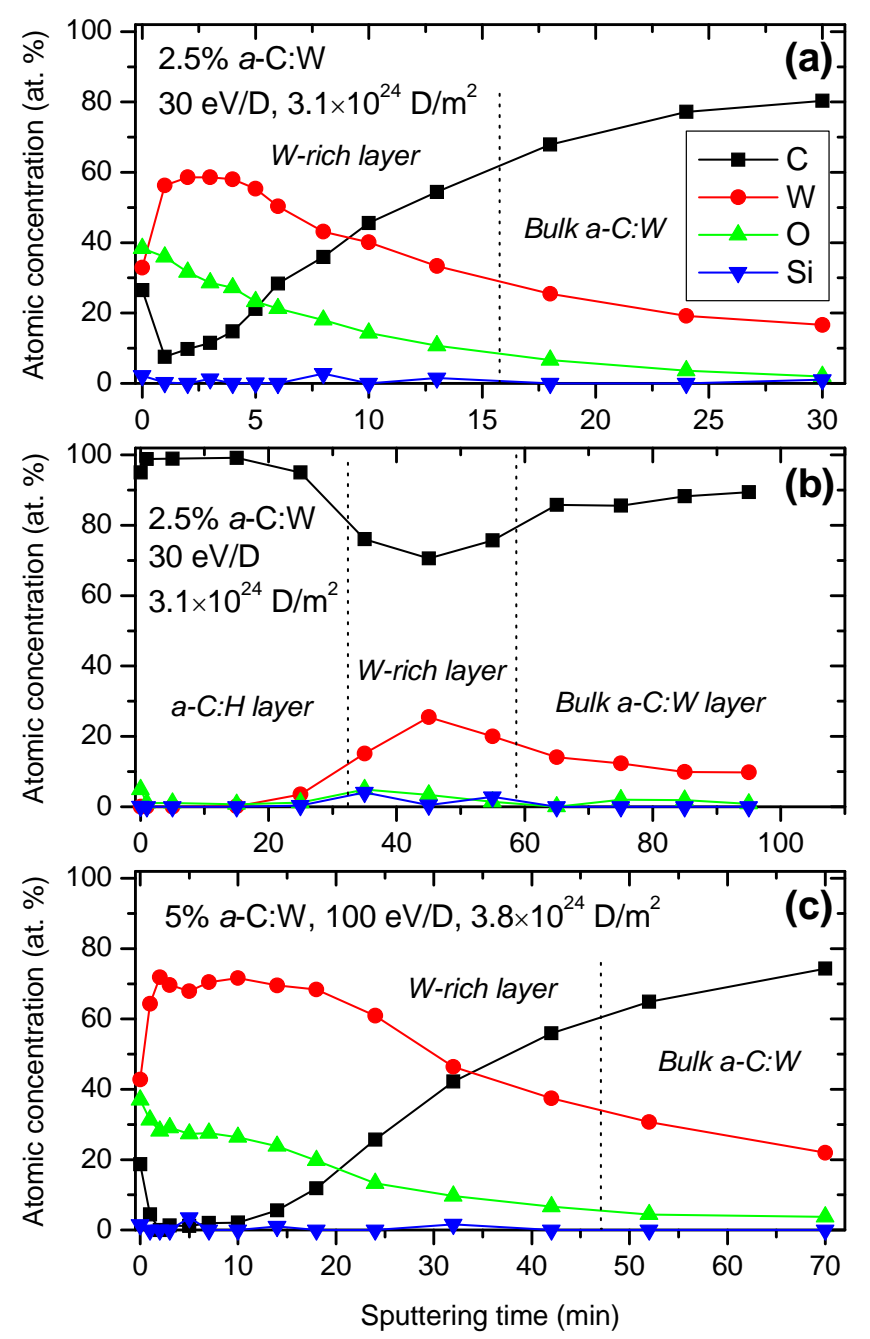

Fig. 6. Depth profiles of carbon, tungsten, oxygen and silicon for ( $a, b), 2.5 \% a-C: W$ films exposed to deuterium plasma at $30 \mathrm{eV} / \mathrm{D}$ incident particle energy with a fluence of $3.1 \times 10^{24} \mathrm{D} / \mathrm{m}^{2}$ and (c) $5 \% \mathrm{a}-\mathrm{C}: \mathrm{W}$ film exposed to deuterium plasma at $100 \mathrm{eV} / \mathrm{D}$ with a fluence of $3.8 \times 10^{24} \mathrm{D} / \mathrm{m}^{2}$. For (b) a dense hydrogenated amorphous carbon films was deposited onto the surface directly after D plasma exposure without breaking vacuum to avoid air contact of the film. The positions of the interfaces between the $W$-rich layer and the bulk of the $a-C: W$ film are roughly indicated by the vertical lines.

after plasma exposure. However, we also find significant amounts of oxygen distributed throughout the whole W-rich layer. Before we come to the discussion of the measured XPS depth profiles, we make a comment regarding the measured oxygen concentrations. The oxygen concentration can be attributed to two different possible processes: Impurity implantation during plasma erosion or oxidation during air exposure. Water is a common impurity in vacuum systems. During plasma erosion water desorption from the chamber walls could lead to a certain impurity fraction in the plasma and oxygen ions could be implanted into the $\mathrm{W}$-rich layers. On the other hand, taking into account the porous structure of the Wrich layer it is quite probable that during air exposure oxygen can penetrate into the $\mathrm{W}$-rich layer and oxidize the inner surfaces of the cavities. The following experiment was conducted to distinguish these two possible explanations for the measured oxygen content: To avoid the effect of oxidation during air exposure, a $2.5 \%$ a-C:W film was eroded in a deuterium plasma similarly as the sample shown in Fig. 4a. Directly after erosion a dense hydrogenated amorphous carbon film was deposited onto the W-rich film in the PlaQ chamber without breaking the vacuum. The thickness of this hard $a-\mathrm{C}: \mathrm{H}$ film was more than $50 \mathrm{~nm}$. Details of $a-\mathrm{C}: \mathrm{H}$ deposition and the corresponding film properties can be found in Refs. [15] and [16], 
respectively. This cover layer of hard $a-\mathrm{C}: \mathrm{H}$ should prevent oxidation of the $\mathrm{W}$-rich layer during transport through air. Fig. $6 \mathrm{~b}$ shows the composition depth profile of this $2.5 \% a-\mathrm{C}: \mathrm{W}$ film with a protective $a$-C:H layer. In the plot three different regions can be distinguished. On top is the $a-\mathrm{C}: \mathrm{H}$ cover layer followed by the W-rich layer in the middle and the underlying bulk $a-\mathrm{C}: \mathrm{W}$ film. The carbon concentration in the W-rich layer is much higher than in Fig. 6a. This is most probably due to deposition of $a-\mathrm{C}: \mathrm{H}$ into the open porosity of the $\mathrm{W}$-rich layer. Directly at the surface of the $a-\mathrm{C}: \mathrm{H}$ film about $8 \%$ absorbed oxygen are present, but inside the $a-\mathrm{C}: \mathrm{H}$ film the oxygen concentration is below the detection limit. The $\mathrm{O} / \mathrm{W}$ ratio in the $\mathrm{W}-$ rich layers is only about 0.1 which is significantly lower than the $\mathrm{O} / \mathrm{W}$ ratio in Fig. $6 \mathrm{a}$ of about 0.3 to 0.5 . Even in the bulk of the $a-\mathrm{C}: \mathrm{W}$ film the oxygen fraction in Fig. $6 \mathrm{~b}$ is lower than in Fig. 6a. From these data we conclude that most of the oxygen found in the W-rich layer shown in Fig. $6 \mathrm{a}$ is due to air exposure after plasma treatment and not due to implantation during plasma erosion. Although it can not be excluded that the amount of oxygen found in the experiments with the $a-\mathrm{C}: \mathrm{H}$ cover layer is due to implantation during plasma erosion, we believe that this oxygen is also due to air exposure.

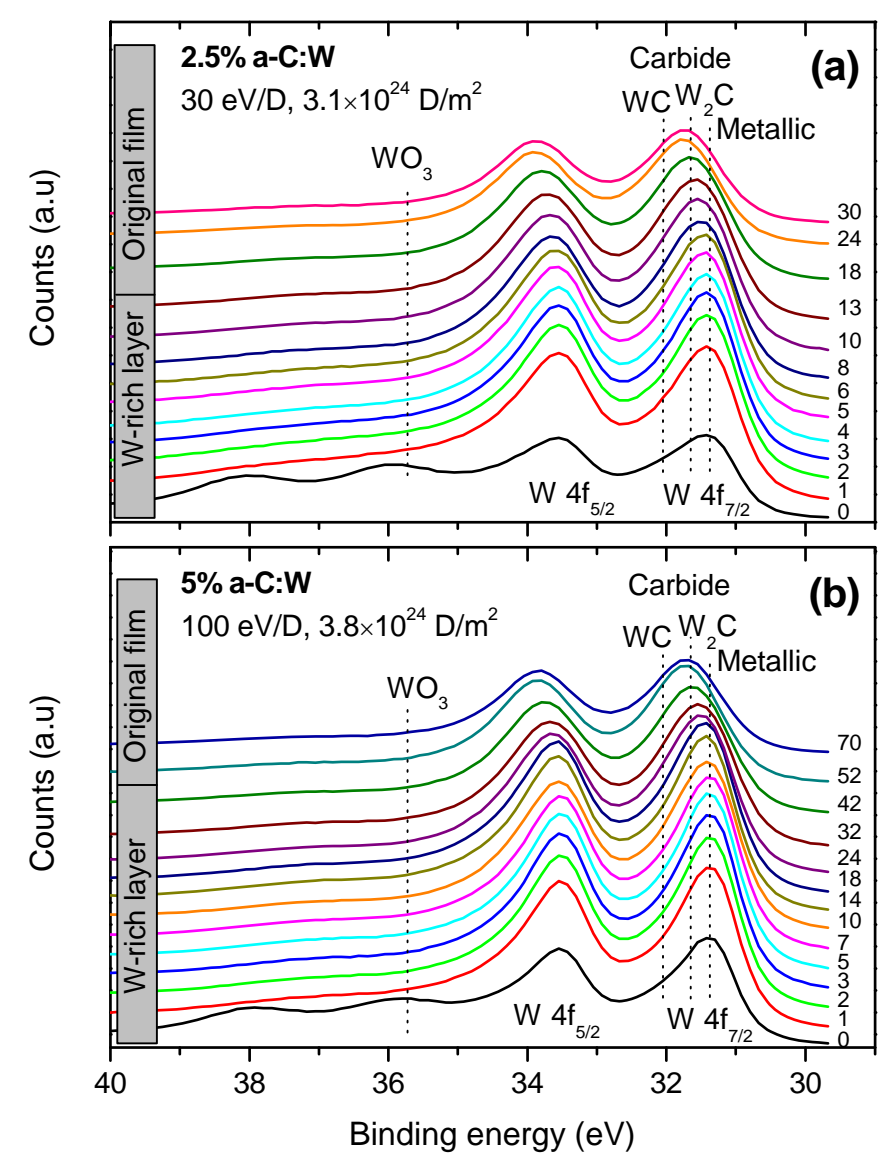

Fig. 7. The evolution of XPS $W 4 f$ spectrum of (a) $2.5 \%$ and (b) $5 \%$ a-C: $W$ film exposed to deuterium plasmas with 30 and $100 \mathrm{eV} / \mathrm{D}$ incident particle energies with fluences of $3.1 \times 10^{24}$ and $3.8 \times 10^{24} \mathrm{D} / \mathrm{m}^{2}$, respectively. The corresponding sputtering time (in minutes) is indicated by the numbers at the right-hand side. The separation of $W$-rich layer and original film is indicated schematically at the left-hand side according to Fig. 6. (a) and (c). The individual spectra are vertically shifted for better visibility. The dotted vertical lines indicate the binding energies of oxidic, carbidic and metallic tungsten [27,29-30]. 
The composition depth profile shown in Figs. 6a and c can be subdivided into two parts. This separation is indicated by the dotted vertical lines in Fig. 6 . The first part on the left-hand side of the line is the W-rich layer formed during deuterium plasma exposure and the second part on the right-hand side is the remaining original film below the W-rich layer. Clearly the transition between the two regions is very smooth and an obvious separation is not straight forward. On the other hand, keeping in mind the porous structure of the films (see Figs. 3 and 4) a clear transition should not be anticipated. The position of the lines was chosen such that the $\mathrm{W}$ signal has roughly decreased to $50 \%$ of its maximum value and they should be consider only as a indication of the transition between the two regions. Both films (Figs. 6a and c) show a relatively high carbon and oxygen concentration directly at the surface which is attributed to exposure to ambient air. After 1 minute $\mathrm{Ar}^{+}$sputtering most of this adsorbed layer is removed. On the $2.5 \% a-\mathrm{C}: \mathrm{W}$ sample (Fig. 6a) a mixed layer consisting of carbon, tungsten and oxygen is present at the surface after plasma exposure with $30 \mathrm{eV} / \mathrm{D}$. As shown above, the oxygen in the mixed layer originates predominantly from air exposure. Therefore, if we take into account only carbon and tungsten, the concentrations of tungsten and carbon in the mixed layer are $87 \%$ and $13 \%$, respectively. Obviously, the tungsten concentration in the mixed layer is much higher than in the as-deposited film, which can be attributed to preferential erosion of carbon [21] during plasma exposure. Since these experiments were performed at $30 \mathrm{eV} / \mathrm{D}$ energy, the ion energy is too low to cause sputtering of $\mathrm{W}$ atoms from the surface because the physical sputtering threshold of tungsten by deuterium is $229 \mathrm{eV}$ [22]. As a consequence, all the $\mathrm{W}$ atoms that were present in the original layer accumulate at the surface in this mixed layer which is called W-rich layer through out this article. Carbon atoms at the surface can be removed by physical sputtering (threshold energy for sputtering of carbon by deuterium is $28 \mathrm{eV}$ [22]) and by chemical sputtering [23]. At the surface all carbon atoms can be removed by physical and chemical sputtering. In deeper layers, in particular beyond the ion penetration range of a few nanometers, carbon atoms can only be eroded by chemical erosion [23]. Consequently, only tungsten atoms should remain in the W-rich layer at the surface after $30 \mathrm{eV} / \mathrm{D}$ energy deuterium plasma exposure. Unexpectedly, about $10 \%$ carbon atoms are still found in this W-rich layer (Fig. 6a). One possible explanation is that the remaining carbon originates from the initial tungsten-carbon chemical bonding in the $a-\mathrm{C}: \mathrm{W}$ film. Although at low deposition temperature no tungsten carbide crystal is formed in asdeposited $a$-C:W films, carbide bonds were shown to be the dominant chemical bonding structure of tungsten in $a-\mathrm{C}: \mathrm{W}$ films [13,24-25]. It is quite probable that not all carbon in the $\mathrm{W}$-rich layer can be removed by chemical erosion under the conditions of our experiment. Another possible explanation of the roughly $10 \%$ carbon found in the W-rich layer is that it originates, as the oxygen, dominantly from adsorbed carbon carrying species on the inner surfaces of the porous film from the contact to ambient atmosphere. But we rule out this explanation, because the carbon content in the W-rich layer in Fig. 6c is significantly lower although the microstructure of the layer is comparable to that of the layer used in Fig. 6a (compare Figs. 3b and 4d) and the sample was also transported through air.

For 5\% $a$-C:W film after exposure to deuterium plasma with $100 \mathrm{eV} / \mathrm{D}$ (Fig. 6c) a W-rich layer with very low carbon concentration formed at the surface and below the carbon concentration increases gradually. That means that a carbon free $\mathrm{W}$-rich layer is formed at the surface of 5\% a-C:W during exposure to higher incident energy $(100 \mathrm{eV} / \mathrm{D})$.

The fact that in the three shown cases the carbon to tungsten ratio in the bulk of the $a-\mathrm{C}: \mathrm{W}$ film is not equal to the W concentration measured by RBS is due to preferential sputtering of $\mathrm{C}$ which causes enrichment of $\mathrm{W}$ at the surface during depth profiling. Because XPS is very surface sensitive, the W enrichment leads to a higher XPS signal and does not reflect the bulk value.

In Fig. 7 the evolution of the XPS W 4 f spectrum of (a) $2.5 \%$ and (b) $5 \% a$-C:W film after exposure to 30 and $100 \mathrm{eV} / \mathrm{D}$ incident particle energies is shown. The spectra are plotted 
without background subtraction and the binding energies of $\mathrm{WO}_{3}$, carbidic and metallic tungsten are marked by dotted lines. The binding energy of the metallic $W 4 \mathrm{f}_{7 / 2}$ peak is $31.4 \mathrm{eV}$ [26-28] and the binding energies of two different tungsten carbide phases, WC and $\mathrm{W}_{2} \mathrm{C}$ are 31.8 and $32.0 \mathrm{eV}$ [27, 29-30], respectively. The various $\mathrm{W}$ oxides have strongly varying peak positions. The $\mathrm{W} 4 \mathrm{f}_{7 / 2}$ peak of $\mathrm{WO}_{3}$ is located at $35.8 \mathrm{eV}[31,32]$, the substoichiometric $\mathrm{WO}_{3-\mathrm{x}}(\mathrm{x}<1)$ at about $34.5 \mathrm{eV}$ [31] and $\mathrm{WO}_{2}$ at $32.9 \mathrm{eV}$ [28].

In both cases (Figs. 7a and b), the $\mathrm{W} 4 \mathrm{f}$ spectrum of the initial surface can be decomposed into two well separated doublets, the one with $\mathrm{W} 4 \mathrm{f}_{7 / 2}$ peak at $35.8 \mathrm{eV}$ corresponds to the $\mathrm{W}^{6+}$ oxidation state in tungsten trioxide and the second doublet with the $\mathrm{W}_{4 / 2}$ peak at $31.4 \mathrm{eV}$ corresponds to $\mathrm{W}$ in the metallic state. Possibly also existing $\mathrm{WO}_{3-\mathrm{x}}$ phases cannot be resolved and may be hidden in the high energy tail of the metallic $\mathrm{W}_{4} \mathrm{f}_{7 / 2}$ peak. After 1 minute $\mathrm{Ar}^{+}$ sputtering, the $\mathrm{WO}_{3}$ peak has vanished and the spectrum is dominated by the doublet with the $\mathrm{W} 4 \mathrm{f}_{7 / 2}$ peak at $31.8 \mathrm{eV}$. Since we know from the oxygen peak that oxygen is still present in the sample, this oxygen has to be present in the form of $\mathrm{WO}_{3-\mathrm{x}}$ and $\mathrm{WO}_{2}$. These contributions are not well resolved in the spectra shown in Fig. 7. As discussed above, we are convinced that the oxygen found in the $\mathrm{W}$-rich layer is due to transport through air. We, therefore, conclude that after plasma exposure the $\mathrm{W}$ in the $\mathrm{W}$-rich layer is present predominantly in form of metallic W.

Both samples show a similar behaviour during Ar sputter depth profiling. With increasing

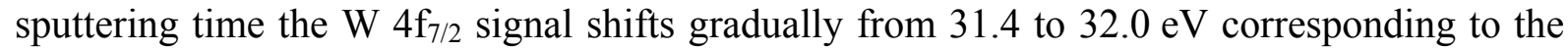
tungsten carbide state. This peak position is in good agreement with the binding energy found in as-deposited $a-\mathrm{C}: \mathrm{W}$ films [24]. Therefore, we assume that at the end of the sputter depth profiling measurements the underlying a-C:W layer has been reached. The difference between the two samples is the time required to reach the a-C:W layer. For the $2.5 \% a-C: W$ film exposed at $30 \mathrm{eV} / \mathrm{D}$ energy (Fig. 7a) it takes about $18 \mathrm{~min}$ Ar sputtering and for the 5\% $a$ $\mathrm{C}: \mathrm{W}$ film exposed at $100 \mathrm{eV} / \mathrm{D}$ energy (Fig. $7 \mathrm{~b}$ ) about $42 \mathrm{~min}$.

\subsection{Carbon erosion}

The carbon amount before and after exposure was determined by RBS and the measured RBS spectra were quantitatively evaluated using the program SIMNRA [19]. Fig. 8 shows the $4 \mathrm{MeV}{ }^{4} \mathrm{He}$ RBS spectra of 5\% a-C:W film before and after plasma exposure with (a) 30 and (b) $100 \mathrm{eV} / \mathrm{D}$ incident particle energy, respectively. Each peak - actually each peak in the asdeposited spectra has more or less the shape of a rectangle - and its height in these RBS spectra correspond to a certain element and its concentration. The width of the peak contains information on the film thickness and the intensity is correlated to the local concentration in a certain depth. Several peaks were detected in RBS spectra of Fig. 8. They correspond to tungsten, argon, silicon, and carbon. The surface position of each element and the corresponding positions of the interface for the as-deposited film are marked by the vertical dashed lines in Fig. 8. For example, the high-energy edge of the $\mathrm{W}$ peak originates from $\mathrm{W}$ atoms at the surface and is marked as $\mathrm{W}_{\text {surface. }}$ The low-energy edge is accordingly due to $\mathrm{W}$ at the interface to the silicon substrate and is marked as $\mathrm{W}_{\text {interface }}$.

Argon in the films originates from the magnetron deposition process. In this process argon is used a sputtering gas and a small fraction of the argon ions is reflected from the sputtering targets as neutral species. These energetic neutrals can reach the substrate and are implanted into the growing film. Quantitative analysis of the RBS spectra yields that the argon content in the magnetron sputtered films is of the order of $1 \%$ for all investigated samples. 


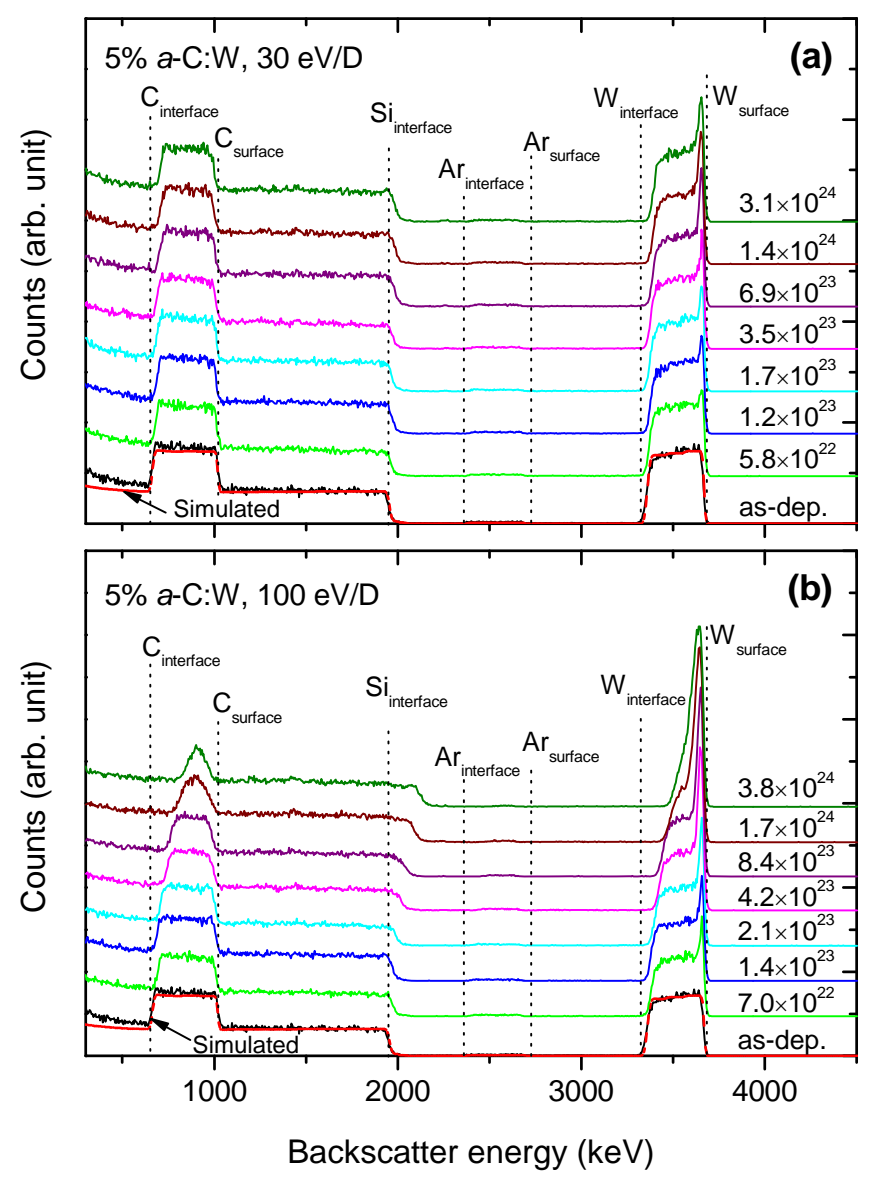

Fig. 8: RBS spectra of $5 \%$ a-C:W films exposed to (a) 30 and (b) $100 \mathrm{eV} / \mathrm{D}$ incident particle energies as a function of fluence. The exposure fluences are indicated in the figure (in atoms $/ \mathrm{m}^{2}$ ). Simulated spectra for as-deposited films are also presented. The backscattering energies for different atoms at the surface and at the interface to the substrate of the asdeposited film are marked by dotted lines for $C, S i, A r$, and $W$. The individual spectra are vertically shifted for better visibility.

After deuterium exposure the intensity of the $\mathrm{W}$ peak increases at the high-energy side, and the low-energy edge of the $\mathrm{W}$ peak shifts towards higher energy. The shift of the W lowenergy edge towards higher energy is due to the decrease in total film thickness. The increase of $\mathrm{W}$ peak intensity at the high-energy side is attributed to tungsten accumulation at the sample surface. Obviously, the measured intensity of the $\mathrm{W}$ surface signal at $100 \mathrm{eV} / \mathrm{D}$ energy (Fig. 8b) is much higher than that at $30 \mathrm{eV} / \mathrm{D}$ (Fig. 8a) after comparable exposure duration. That means that the tungsten surface concentration in the former is significantly higher than in the latter.

From the SIMNRA analysis of the RBS spectra shown in Fig. 8 we find that for $30 \mathrm{eV} / \mathrm{D}$ incident energy the total $\mathrm{W}$ amount in the film remains unchanged. However, at $100 \mathrm{eV} / \mathrm{D}$ the total $\mathrm{W}$ amount decreases and about $2.9 \times 10^{20} \mathrm{~W} / \mathrm{m}^{2}$ is removed after exposure to a fluence of $3.8 \times 10^{24} \mathrm{D} / \mathrm{m}^{2}$. As mentioned in the experimental section, the deuterium ion flux reaching the surface contains about $3 \% \mathrm{D}^{+}$ions (corresponding to $1 \%$ of the impinging deuterons in form of ions). At $100 \mathrm{eV} / \mathrm{D}$ incident energy (corresponding to $\mathrm{D}_{3}{ }^{+}$ions with $300 \mathrm{eV}$ ) $\mathrm{D}^{+}$ions impinge on the surface with energy of $300 \mathrm{eV}$. This exceeds the threshold for physical sputtering of tungsten by D $(229 \mathrm{eV})$ [22] and leads to the observed loss of tungsten. From this removed $\mathrm{W}$ amount and the integrated $\mathrm{D}^{+}$ion fluence $(1 \%$ of total $\mathrm{D}$ fluence, see Sect. 2$)$ we calculate a sputtering yield of $(5$ to 8$) \times 10^{-3}$. This yield is about a factor of 20 to 35 higher than the sputtering yield of bulk W material $\left(2.3 \times 10^{-4}\right)[18]$. A possible explanation for this 
obvious mismatch is that the porous structure of this W-rich layer (Fig. 4c and d) could cause a higher sputtering yield. However, a contribution of impurity sputtering to the observed sputter rate cannot be ruled out.

Another obvious change with D fluence in the spectra of Fig. 8 is the strong decrease of the integral intensity of the carbon peak. In contrast to $\mathrm{W}$ both edges of the $\mathrm{C}$ peak shift. Again the shift of the low-energy edge is due to the decrease in total film thickness. The shift of the high-energy edge to lower energy indicates that $\mathrm{C}$ is no longer present at the sample surface. Furthermore, in Fig. 8b the low- and high-energy edges of the carbon peaks which were exposed to fluences of about $1 \times 10^{24} \mathrm{D} / \mathrm{m}^{2}$ and more (topmost 3 spectra) are much less steep than those in the other spectra. A comparable reduced steepness of the edges is found for the low-energy side of the $\mathrm{W}$ peaks and for the silicon interface. The reduced steepness of the high-energy sides of the $\mathrm{C}$ and $\mathrm{Si}$ peaks as well as the low energy side of the $\mathrm{W}$ peak can be attributed to the microstructure of the W-rich (see Figs. 3 to 5). Although AFM indicates that the surface of the $5 \% a-\mathrm{C}: \mathrm{W}$ film after deuterium plasma exposure at $100 \mathrm{eV} / \mathrm{D}$ with a fluence of $3.8 \times 10^{24} \mathrm{D} / \mathrm{m}^{2}$ is still relatively smooth with a roughness in the $\mathrm{nm}$ range, the corresponding cross-section image (Fig. 4d) shows a highly porous structure below the surface. As a result, the analysing ion beam probes locally very different film thicknesses which leads to the reduced steepness of both sides of the peak.

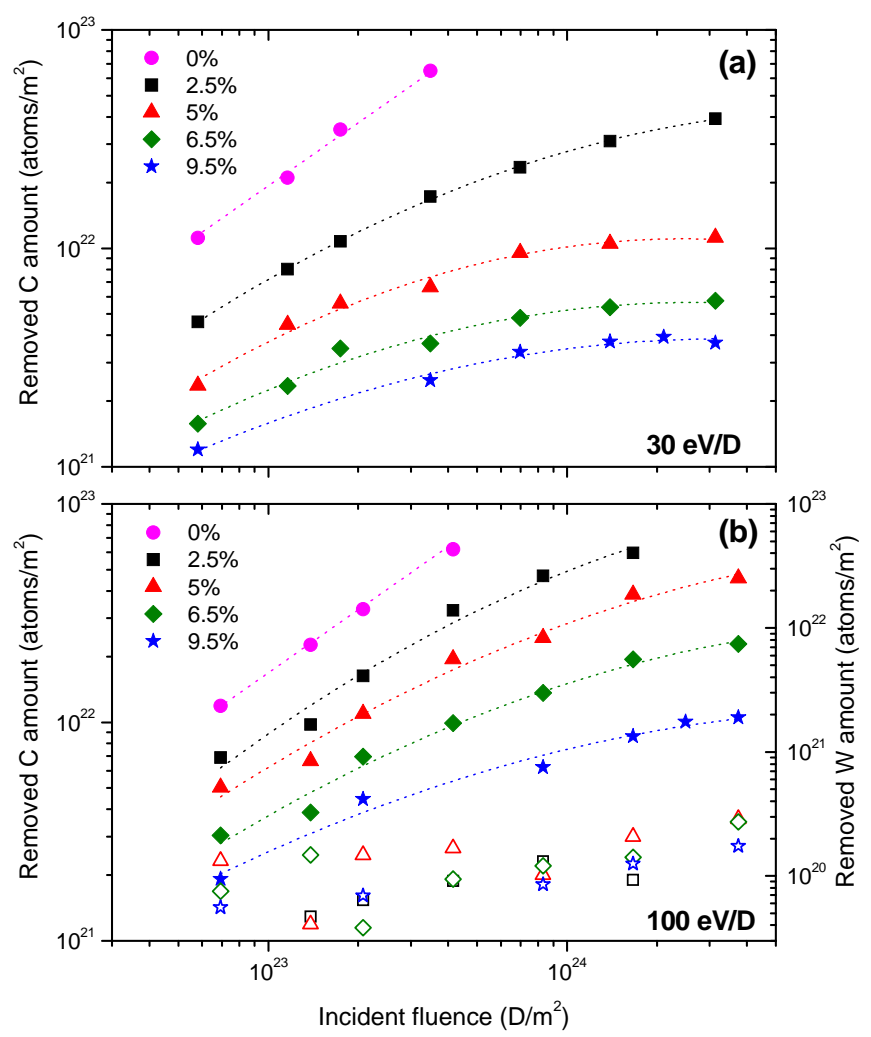

Fig. 9. Removed carbon amount of $a-C$ and $a-C: W$ films (filled symbol) as a function of the incident fluence at 30 (a) and $100 \mathrm{eV/D}$ (b) incident particle energy. The removed tungsten amount of a-C:W films at $100 \mathrm{eV/D}$ incident energy (open symbol) is also shown in Fig. 9(b); note the different scale for the removed $W$ amount.

The removed carbon amount of $a-\mathrm{C}$ and $a-\mathrm{C}: \mathrm{W}$ films is summarized in Fig. 9 as a function of incident fluence at 30 (a) and $100 \mathrm{eV} / \mathrm{D}$ (b) incident particle energy. Pure amorphous carbon films were also eroded. Due to the film thickness limitation (thicker films tend to peel off) and the rather high erosion rate of $a$-C films, only a few data points were obtained for D fluences well below $10^{24} \mathrm{D} / \mathrm{m}^{2}$. For the $a-\mathrm{C}$ film the removed carbon amount 
increases linearly with increasing fluence. This is the anticipated behaviour for erosion with constant erosion rate. The time-averaged carbon removal rates are about $9.2 \times 10^{18}$ atoms $\cdot \mathrm{m}^{-2} \cdot \mathrm{s}^{-}$ ${ }^{1}$ at $30 \mathrm{eV} / \mathrm{D}$ and about $9.6 \times 10^{18}$ atoms $\cdot \mathrm{m}^{-2} \cdot \mathrm{s}^{-1}$ at $100 \mathrm{eV} / \mathrm{D}$, corresponding to erosion yields of 0.17 and 0.16 , respectively. These erosion yields are about 5 to 10 times higher compared to data obtained by exposure of different carbon materials to deuterium ion beams [23], in which only deuterium ions participate in the erosion. But in a deuterium plasma the additionally impinging flux of highly reactive neutral atomic deuterium which is at least one order of magnitude higher than the ion flux [17], causes enhanced chemical sputtering [23,33-36]. We assume that this is the explanation for the observed higher erosion yield in our experiment.

For $a-\mathrm{C}: \mathrm{W}$ films, the carbon removal rate is significantly lower than for pure $a$-C films. It decreases strongly with increasing $\mathrm{W}$ concentration. In addition, it decreases with incident fluence. At a deuterium energy of $30 \mathrm{eV} / \mathrm{D}$ and a fluence of $5.8 \times 10^{22} \mathrm{D} / \mathrm{m}^{2}$, the carbon removal rates reduce by doping with $2.5 \%$ and $9.5 \%$ tungsten to about $3.8 \times 10^{18}$ and $1.0 \times 10^{18}$ atoms $\cdot \mathrm{m}^{-2} \cdot \mathrm{s}^{-1}$, i.e., they drop by a factor between 2 to 9 compared with pure $a$-C film. For $2.5 \% a-\mathrm{C}: \mathrm{W}$ film more than $60 \%$ of the carbon atoms are removed after a fluence of $3.1 \times 10^{24} \mathrm{D} / \mathrm{m}$ and the data indicate a further continuous removal. This result is in good agreement with the data deduced from the SEM cross-section image, in which the thickness of film decreased from initially $760 \mathrm{~nm}$ to about $300 \mathrm{~nm}$ after plasma exposure. For higher tungsten concentrations in the films (5\% and 6.5\%), the removed carbon amounts tend to saturate after a fluence above $10^{24} \mathrm{D} / \mathrm{m}^{2}$. For even higher tungsten concentration $(9.5 \%)$, the carbon removal clearly saturates, i.e., the removed carbon amount does not change any more after a fluence of $1.0 \times 10^{24} \mathrm{D} / \mathrm{m}^{2}$ suggesting that the residual carbon is shielded by the W-rich layer from further erosion. As these experiments were performed at $30 \mathrm{eV} / \mathrm{D}$ so that carbon atoms are preferentially eroded, but no $\mathrm{W}$ atoms can be sputtered, all $\mathrm{W}$ atoms from the original layer remain at the surface and form a W-rich top layer. This W-rich layer plays a protective role and prevents the transmission of the reactive species thus reducing the reaction with the remaining carbon atoms. As the thickness of this W-rich layer increases with fluence it decreases the removal efficiency and leads to a decrease of the erosion rate with fluence. It is reasonable to assume that the erosion process will stop if the $\mathrm{W}$-rich layer is thick or compact enough to completely block the transmission of the reactive species.

In Fig. 5a and $\mathrm{b}$ it is shown that a compact thin $\mathrm{W}$-rich layer is formed at the surface of the 9.5\% $a-\mathrm{C}: \mathrm{W}$ film which stops the erosion process. However, for the $2.5 \% a-\mathrm{C}: \mathrm{W}$ film a several hundred nm thick W-rich layer is formed at the surface (Fig. 3). Although this thick layer leads to a decrease of the erosion rate it doesn't stop further carbon erosion in the investigated fluence range. According to the simulation of the RBS spectrum the total $\mathrm{W}$ areal density in the $\mathrm{W}$-rich layer of this $2.5 \% a-\mathrm{C}: \mathrm{W}$ film is determined to $1.04 \times 10^{21} \mathrm{~W} / \mathrm{m}^{2}$. This would correspond to a layer thickness of $16 \mathrm{~nm}$ if $\mathrm{W}$ bulk density $\left(19.3 \mathrm{~g} / \mathrm{cm}^{3}\right)$ would be assumed. However, the actual thickness measured by SEM is about $300 \mathrm{~nm}$. That means, if only $\mathrm{W}$ atoms are accounted for, the porosity of the $\mathrm{W}$-rich layer is close to $95 \%$, so that the $\mathrm{W}$-rich layer formed at the surface of the $2.5 \% a-\mathrm{C}: \mathrm{W}$ film is more similar to tungsten foam (Fig. 3b). Since it is difficult to define a precise interface between the $\mathrm{W}$-rich layer and the underlying original a-C:W film this value for the porosity has, as well as the other values following below, a rather high uncertainty. The penetration depths of the impinging low energy deuterium ions at 100 and $300 \mathrm{eV}$ are 4 and $8 \mathrm{~nm}$, respectively [18]. In porous material it would be correspondingly higher, e.g., in the highly porous W-rich layer shown in Figs. 3a and $b$ the penetration depth for the small contribution of $\mathrm{D}^{+}$ions impinging in this case with $100 \mathrm{eV}$ (about $3 \%$ ) would at most be $80 \mathrm{~nm}$. For the case shown in Fig. $3 \mathrm{~d}$ the $\mathrm{D}^{+}$ions impinge with $300 \mathrm{eV}$ and the corresponding nominal ion penetration range in the porous material (97\% porosity) would at most be $270 \mathrm{~nm}$, but $\mathrm{C}$ is removed from the complete remaining $480 \mathrm{~nm}$ thick W-rich layer. Consequently, we do not believe that the erosion at the interface to the underlying C-rich layer is due to ions. Rather we assume that highly reactive 
neutral species are responsible for the continuous erosion of carbon. As already mentioned above the flux of atomic hydrogen reaching the sample surface is at least a factor of 10 higher than the ion flux [17]. Deuterium atoms can penetrate this high-porosity W-rich layer via multiple collisions with the internal surfaces of the pores and channels. Naturally, the D atoms have to survive a sufficiently high number of wall collisions to be able to reach the carbon interface. Once the D atoms have reached the interface, they can react with carbon atoms forming volatile hydrocarbon species which diffuse through the W-rich layer and desorb. But a deeper understanding of the involved processes needs further studies. Interestingly, the porosity of the W-rich layer formed at the surface of $9.5 \%$ a-C:W film (Fig. $5 b$ ) is about $50 \%$. This is still a very porous structure compared with bulk $\mathrm{W}$, but it is much more compact than the W-rich layer formed in the $2.5 \% a-\mathrm{C}: \mathrm{W}$ film. Obviously, this layer is dense enough to block the reactive species and stop the erosion process. It has to be added that the determination of the layer thickness from the SEM image is in this case even more difficult than difficult than for Figs. 3 and 4 and, therefore, has an even larger uncertainty so that the real porosity could be significantly lower.

At higher deuterium energy $(100 \mathrm{eV} / \mathrm{D}$, Fig. $9 \mathrm{~b})$, all carbon atoms in the $2.5 \% a-\mathrm{C}: \mathrm{W}$ film were completely removed after a fluence of $1.7 \times 10^{24} \mathrm{D} / \mathrm{m}^{2}$. This result is in good agreement with the SEM cross-section images (Fig. 3d). For higher tungsten concentrations in the films, the removed carbon amounts increase monotonically with increasing fluence, but the erosion rate decreases continuously. A saturation of the carbon removal, as found for $30 \mathrm{eV} / \mathrm{D}$ incident species energy, is not observed in the investigated fluence range at $100 \mathrm{eV} / \mathrm{D}$. This difference can not be simply attributed to the energy difference because the ion implantation depth is much smaller than the thickness of the W-rich layer. Assuming that impinging ions are blocked by the $\mathrm{W}$-rich layer and that only atomic hydrogen can penetrate the porous layer and react with carbon blow it, it is reasonable to anticipate that the erosion rates for two incident energies should be the same because the flux of the atomic deuterium is the same. However, the results show that the erosion rates at $100 \mathrm{eV} / \mathrm{D}$ are significantly higher compared with $30 \mathrm{eV} / \mathrm{D}$. Three possible effects may contribute to the observed difference.

The first effect is the occurrence of W sputtering at higher ion energy. For $9.5 \% a-\mathrm{C}: \mathrm{W}$ films the porosity of the W-rich layers is almost the same for both energies, in this case $\mathrm{W}$ sputtering due to impinging $\mathrm{D}^{+}$ions plays a role. As mentioned above, slight tungsten sputtering during deuterium exposure can be detected at $100 \mathrm{eV} / \mathrm{D}$ incident species energy. As discussed before, this sputtering is attributed to the small fraction of $\mathrm{D}^{+}$ions impinging with $300 \mathrm{eV}$. The amount of removed tungsten from $a-\mathrm{C}: \mathrm{W}$ films (open symbols) is also plotted in Fig. 9b. The measured data scatter strongly and most data are below $3.0 \times 10^{20} \mathrm{~W} / \mathrm{m}^{2}$. In spite of the scatter a clear monotonic increase with increasing fluence is found. The removed tungsten amounts for the $5 \%, 6.5 \%$ and $9.5 \% a-\mathrm{C}: \mathrm{W}$ films after a fluence of $3.8 \times 10^{24} \mathrm{D} / \mathrm{m}^{2}$ at $100 \mathrm{eV} / \mathrm{D}$ are $2.9,2.6$ and $1.8 \times 10^{20} \mathrm{~W} / \mathrm{m}^{2}$, respectively. The values correspond to about $10 \%$ of the total amount of $\mathrm{W}$ in the $\mathrm{W}$-rich layer. Although the tungsten sputtering reduces the thickness of the W-rich layer at the surface and thereby increases the transmission of reactive species through the W-rich layer, we believe that this effect is not strong enough to explain the observed increase of the carbon erosion rate by a factor of 3 .

The second is the increased porosity of the W-rich layer. Although in some cases, i.e., at low $\mathrm{W}$ concentration $(<5 \%)$, atomic deuterium can penetrate the $\mathrm{W}$-rich layer, we also found other cases where the W-rich layer is dense enough to block the penetration of atomic deuterium (Fig. 5a and b). That means the W-rich layer not only blocks impinging ions, but its morphology also greatly affects the transport of atomic deuterium through it. The porosities of the $\mathrm{W}$-rich layers formed at $30 \mathrm{eV} / \mathrm{D}$ in $2.5 \%$ and $5 \% a-\mathrm{C}: \mathrm{W}$ films are $95 \%$ and $85 \%$, respectively, as deduced from analysis of the RBS and SEM data. At higher incident energy the corresponding porosities increase to $97 \%$ and $91 \%$, respectively. This increase of porosity at higher incident species energy is also directly visible in the SEM surface and cross-section 
images (Fig. 3 and 4). Increased porosity enhances penetration of atomic deuterium; as a result the erosion rate at higher incident energy increases.

A third effect that may explain the observed increase of the carbon removal rate is a temperature increase in the W-rich layer and at the interface to the C-rich layer. It is well known that the chemical erosion of $\mathrm{C}$ by atomic $\mathrm{D}$ is strongly temperature dependent [23]. The increased energy input into the surface due to the higher energy of impinging ions could lead to a slight temperature increase and could therefore explain the high $\mathrm{C}$ removal rate.

Both latter processes may simultaneously contribute to the enhanced carbon erosion at $100 \mathrm{eV} / \mathrm{D}$. The driving force for the evolution of the different morphologies of the W-rich layers is presently unknown. We may postulate that the increased energy input into the surface may cause an increase of the surface temperature, but we have no experimental proof for this hypothesis.

\section{Conclusion}

The erosion behaviour of tungsten-doped amorphous carbon films in low-temperature deuterium plasmas was studied. The erosion of $a-\mathrm{C}: \mathrm{W}$ films depends sensitively on the film composition and the erosion conditions. For W-doped films the erosion rate is significantly lower than the rate of pure $a-\mathrm{C}$ films and it decreases significantly with increasing W concentration. Furthermore, the erosion rate of $a-\mathrm{C}: \mathrm{W}$ films decreases with increasing incident fluence because carbon is preferentially eroded while tungsten atoms remain at the surface forming a W-rich layer which protects the carbon underneath from further erosion. XPS analyses show that the W-rich layer formed at the surface during the deuterium plasma exposure to $30 \mathrm{eV} / \mathrm{D}$ incident energy consists predominantly of metallic tungsten and with less than $10 \%$ tungsten carbide. At low impinging species energy $(30 \mathrm{eV} / \mathrm{D})$ and for $\mathrm{W}$ concentrations of $6.5 \%$ and higher the erosion process stops above a fluence of about $10^{24} \mathrm{D} / \mathrm{m}^{2}$. SEM cross-section images indicate that for these higher $\mathrm{W}$ concentrations a relatively compact $\mathrm{W}$-rich layer is formed at the surface which blocks the transmission of reactive deuterium species which are responsible for carbon erosion in deep layers and thus prevents further erosion. In contrast, for lower W concentrations $(<6.5 \%)$ thick W-rich layers with high porosity are formed which allow transmission of highly reactive neutral species thus enabling continuous erosion. At $100 \mathrm{eV} / \mathrm{D}$ incident energy slight tungsten sputtering was detected due to the small fraction of $\mathrm{D}^{+}$ions from the plasma which impinge with $300 \mathrm{eV} / \mathrm{D}$. This sputtering of tungsten reduces the thickness of the W-rich layer at the surface by about $10 \%$. In addition, the carbon erosion rate is significantly higher compared with $30 \mathrm{eV} / \mathrm{D}$, two effects are considered to contribute to the enhanced carbon erosion at higher incident energy. First, increasing incident energy leads to an enhanced porosity of the W-rich layer, which increases the transport of atomic species through the W-rich layer. Second, the higher energy input into the surface may cause surface heating and thus increase the carbon removal rate

\section{Acknowledgements}

The stay of P. Wang at Max-Planck Institute for Plasma Physics in Garching was funded through a bilateral agreement between Max-Planck Society and the Chinese Academy of Sciences which is gratefully acknowledged. Thanks are further due to Michael Fußeder and Joachim Dorner for help with the RBS measurements. 


\section{References}

[1] R. P. Doerner, J. Nucl. Mater. 363-365 (2007) 32.

[2] W. Jacob, J. Nucl. Mater. 337-339 (2005) 839

[3] C. K. Tsui, A. A. Haasz, J. W. Davis, J. P. Coad, J. Likonen, Nucl. Fusion. 48 (2008) 035008.

[4] Y. Hirooka, N. Noda, C. H. Wu, J. Nucl. Mater. 271-272 (1999) 526.

[5] G. Federici, C. H. Skinner, J. N. Brooks, et al., Nucl. Fusion. 41 (2001) 1967.

[6] D. Hildebrandt, P. Wienhold, W. Schneider, J. Nucl. Mater. 290-293 (2001) 89.

[7] J. Roth, E. Tsitrone, A. Loarte, J. Nucl. Mater390-391 (2009) 1.

[8] J. Roth, E. Tsitrone, T. Loarer, et al., Plasma Phys. Control. Fusion 50 (2008) 1.

[9] R. A. Causey, J. Nucl. Mater. 300 (2002) 91.

[10] K. Sugiyama, K. Krieger, C.P. Lungu, J. Roth, J. Nucl. Mater. 390-391 (2009) 659.

[11] R.J. Hawryluk et al., Nucl. Fusion 49 (2009) 065012.

[12] M. Balden, B. T. Cieciwa, I. Quintana, et al., Surf. Coat. Technol. 200 (2005) 413.

[13] M. Balden, Thin Solid Films 519 (2011) 4032-4036.

[14] C. Adelhelm, Ph.D Thesis, "Structure and Erosion Behavior of Metal-doped Carbon Films", IPP Report Number: IPP 17/11, Max-Planck-Institut für Plasmaphysik, Garching (2008).

[15] B. Landkammer, A. von Keudell, W. Jacob, J. Nucl. Mater. 264 (1999) 48.

[16] T. Schwarz-Selinger, A. von Keudell, and W. Jacob, J. Appl. Phys. 86, (1999) 3988.

[17] A. Manhard, T. Schwarz-Selinger, W. Jacob, Plasma Sources Sci. Technol. 20 (2011) 015010. Note: Unfortunately, the information given in the last paragraph of this article is not correct, but the information in figures 5 and 6 is correct. The contribution of the molecular ions to the total ion flux for standard conditions is: $\mathrm{D}_{3}{ }^{+}=94 \%, \mathrm{D}_{2}{ }^{+}=3 \%$, and $\mathrm{D}^{+}=3 \%$. Correspondingly, the contributions to the total deuteron flux in form of ions are: $97 \%, 2 \%$, and $1 \%$.

[18] W. Eckstein, „Calculated sputtering, reflection and range values“, IPP Report Number: IPP 9/132, Max-Planck-Institut für Plasmaphysik, Garching (2008), p. 139, 211, and 213, respectively.

[19] M. Mayer, „SIMNRA User’s Guide“, IPP Report Number: IPP 9/113, Max-Planck-Institut für Plasmaphysik, Garching (1997).

[20] MultiPak, Physical Electronics.

[21] H. Plank, W. Eckstein, Nucl. Instr. and Meth. in Phys. Res. B. 124 (1997) 23.

[22] W. Eckstein, Sputtering yields, in: R. Behrisch, W. Eckstein (Eds.), Sputtering by Particle Bombardment IV, Springer Verlag, Berlin, 2007, p. 142.

[23] W. Jacob, J. Roth, Chemical Sputtering, in: R. Behrisch, W. Eckstein (Eds.), Sputtering by Particle Bombardment IV, Springer Verlag, Berlin, 2007, pp. 329-400.

[24] P. Wang, W. Jacob, M. Balden, A. Manhard, T. Schwarz-Selinger, J. Nucl. Mater. 420 (2011) 101.

[25] Ch. Adelhelm, M. Balden, M. Rasinski, S. Lindig, et al., Surf. Coat. Technol. 205 (2011) 4335.

[26] Ch. Linsmeier, K. Ertl, J. Roth, A. Wiltner, K. Schmid, F. Kost, S.R. Bhattacharyya, M. Baldwin, R.P. Doerner, J.Nucl. Mater. 363-365 (2007) 1129.

[27] J. Luthin, Ch. Linsmeier, Surf. Sci. 454-456 (2000) 78.

[28] A. Katrib, F. Hemming, P. Wehrer, et al., J. Elec. Spec. Rel. Phenom. 76 (1995) 195.

[29] Ch. Linsmeier, J. Luthin, K. U. Klages, A. Wiltner, P. Goldstraß, Phys. Scr. 111 (2009) 86.

[30] Ch. Linsmeier, J. Luthin, P. Goldstraß, J. Nucl. Mater. 290-293 (2001) 25.

[31] F. Bussolotti, L. Lozzi, M. Passacantando, et al., Surf. Sci. 538 (2003) 113.

[32] J. I. Jeong, J. H. Hong, J. H. Moon, J.-S. Kang, Y. Fukuda, J. Appl. Phys. 79 (1996) 9343.

[33] C. Hopf, A. von Keudell, W. Jacob, J. Appl. Phys. 94 (2003) 2373.

[34] M. Schlüter, C. Hopf, T. Schwarz-Selinger, W. Jacob, J. Nucl. Mater. 376 (2008) 33.

[35] W. Jacob, C. Hopf, M. Schlüter, Phys. Scr. T124 (2006) 32.

[36] M. Balden, E. de Juan Pardo,H. Maier, P. Starke, U. Fantz, Phys. Scr. T111 (2004) 123. 